\title{
When the professional becomes personal
}

\section{Mercedes J. Szpunar, MD, PhD}

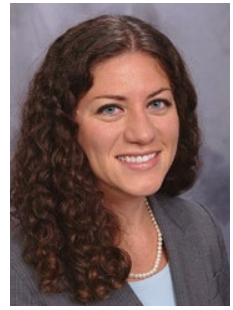

Dr. Szpunar is a PGY-6 Advanced Fellow in Women's Health, Department of Psychiatry, Veterans Affairs San Diego Healthcare System, San Diego, California.

\section{Disclosure}

The author reports no financial relationships with any companies whose products are mentioned in this article, or with manufacturers of competing products.

doi: $10.12788 /$ cp.0027

\section{f}

Discuss this article at www.facebook.com/ MDedgePsychiatry (a) arrived at the inpatient psychiatry unit to begin my last overnight call shift as an intern. When I received sign-out from the day-shift resident, Dr. A (all names have been changed to protect anonymity), I was surprised to learn that the medical student assigned for call that day, G, did not present for his shift. In my residency program, a third-year medical student was assigned to accompany an intern during call shifts. While this assignment was for the medical student's "learning purposes," the presence of a medical student was vital for the intern. The high volume of patients who needed to be seen while on call was difficult to manage, and the help of a medical student certainly lessened that burden.

During her shift, Dr. A had texted G regarding his missed shift, but he replied that he was busy with a research project and did not intend to attend his call shift. Dr. A and I agreed that G's behavior was unusual, especially because we had both worked with him before and had found him to be highly motivated and competent. Dr. A said that she was going to follow up with the clerkship director about G's missed shift. While I was initially angry about having to work the call shift alone, I was quickly overcome with patient care. I labored through the night, and then spent the next day sleeping and recovering.

The following morning, I was back on the inpatient unit to start the work week. I was performing my usual morning prerounding when I received shocking news: a medical student had completed suicide on the school's campus. After processing this

news, I asked for the name of the student. It was $\mathrm{G}$.

I sat in disbelief. How could a medical student who was supposed to work with me just 2 days ago have completed suicide? How could such a bright and wellpresenting student decide to end his life? I voiced these thoughts to my colleague, who responded, "He must have been preparing to do it instead of coming to your call shift." This statement hit me like a ton of bricks. Should I have done more to reach out to him? If I had spoken with him, could I have intervened and arrested his planning?

Later, I found out that G had been diagnosed with bipolar disorder. He had shared his diagnosis with some of his classmates and his psychiatry attending. G had wanted to share his success story as someone with mental illness who could have a career in medicine. However, because mental illness carries stigma, the attending had warned $G$ about possible negative consequences in professional settings if he chose to share his diagnosis openly. G expressed disappointment with this advice. Subsequently, he had appeared more withdrawn during his clerkship engagements.

continued

LET YOUR VOICE BE HEARD

CURRENT PsYCHIATRY invites psychiatry residents to share their views on professional or clinical topics for publication in Residents' Voices. E-mail jbauer@mdedge.com for author guidelines. 
As psychiatrists, we expect to have conversations with our patients about thoughts of suicide, but such discussions with our physician colleagues are far from the norm. We know that the rate of suicide in physicians is higher than in the general population ${ }^{1}$ - particularly in women ${ }^{2}$ - but stigma often prevents those who work in medicine from seeking treatment. ${ }^{3}$ Unfortunately, professional requirements and attitudes perpetuate barriers to accessing mental health care. ${ }^{4}$ As long as licensure concerns or other negative professional consequences persist, physicians will avoid seeking potentially life-saving treatment.

I felt guilty for having been angry at $\mathrm{G}$ for missing my call shift. I knew that the sequence of events could not be changed, but that did not stop me from wondering, "What if?" What if I had reached out? What if Dr. A had corresponded differently? If we want to prevent tragic outcomes like G's, then we need to fix our flawed system. We need to allow physicians to seek treatment and share their experience without punitive professional consequences, because suicide is permanent, and there is no undoing.

\section{References}

1. Schernhammer ES, Colditz GA. Suicide rates among physicians: a quantitative and gender assessment (meta-analysis). Am J Psychiatry. 2004;161(12):2295-2302.

2. Duarte D, El-Hagrassy MM, Couto TCE, et al. Male and female physician suicidality: a systematic review and metaanalysis [published online March 4, 2020]. JAMA Psychiatry. 2020;77(6):1-11.

3. Worley LLM. Our fallen peers: a mandate for change. Acad Psychiatry. 2008;32(1):8-12.

4. Center C, Davis M, Detre T, et al. Confronting depression and suicide in physicians: a consensus statement. JAMA. 2003; 289(23):3161-3166

\section{Clinical Point}

Physicians should be able to seek mental health treatment and share their experience without punitive professional consequences 